\title{
UPAYA PENGURANGAN KECACATAN PRODUK PERTANIAN DI AGRO INDUSTRI BERBASISKAN METODE DMAIC (STUDI KASUS PT.BIMANDIRI AGRO SEDAYA)
}

\author{
Made Irma Dwiputranti ${ }^{1)}$, Yasinta Melati ${ }^{2)}$ \\ 1)Program Diploma D3 Administrasi Logistik,Politeknik Pos Indonesia \\ Email:madeirma@poltekpos.ac.id \\ 2)Program Diploma D3 Adminitrasi Logistik, Politeknik Pos Indonesia \\ Email:yasintamelati@gmail.com
}

\begin{abstract}
Abstrak
Pertumbuhan Agrobisnis sangat berkembang khususnya di Indonesia hal ini disebabkan karena banyaknya perusahaan - perusahaan agrobisnis yang muncul mulai dari yang kecil hingga yang besar, mereka berlomba - lomba mendapatkan konsumen dengan meningkatkan kualitas produk dari masing - masing perusahaan. Salah satunya adalah PT Bimandiri Agro Sedaya, perusahaan ini bergerak dibidang usaha pertanian. PT Bimandiri Agro Sedaya memasok kurang lebih 130 jenis komoditas sayuran, dari 130 jenis tersebut produk Jagung Kelobot, Brokoli, dan Bayam Hijau lebih banyak/sering dipesan oleh konsumen, akan tetapi banyak konsumen yang merasa kecewa karena tingginya jumlah produk sayuran yang cacat, jika tidak dikendalikan akan mengurangi jumlah konsumen dan kerugian bagi perusahaan.

Tujuan penelitian ini adalah untuk mengetahui penerapan six sigma dalam mengurangi kecacatan produk sayuran di PT Bimandiri Agro Sedaya apakah masih dalam batas kendali serta upaya perbaikan pencegahan kecacatan produk sayuran di PT Bimandiri Agro Sedaya dengan menggunakan pendekatan Define, Measure, Analyze, Improve (DMAIC). Penelitian ini dilakukan karena adanya keluhan pelanggan terkait dengan kecacatan produk sayuran, metode penelitian yang dilakukan adalah studi kasus, pengumplan data melalui observasi langsung, wawancara dan penyebaran kuesioner.

Hasil dari penelitian ini adalah faktor penyebab kecacatan produk sayuran berasal dari faktor manusia, mesin produksi, metode kerja dan material/bahan baku. Adapun permasalahannya yaitu produk sayuran yang dikirim memiliki fisik yang tidak sempurna (ada luka) dan produk dikirim ke konsumen mengalami pembusukan. Kerusakan produk sayuran berada dalam batas kendali atau memiliki kapabilitas proses yang baik, nilai DPMO sebesar 30.136, 31 dan nilai sigma yang di dapat rata - rata sebesar 3, 39, untuk produk Bayam Hijau didapatkan level sigma yang paling rendah dibandingkan dengan produk sayuran lainnya yakni sebesar 3,29. Usulan perbaikan yang dapat dilakukan untuk mengatasi kerusakan produk sayuran yaitu memberikan pelatihan dan peningkatan keterampilan karyawan dalam mengolah produk sayuran, membuat SOP penyortiran produk sayuran, SOP penyimpanan sayuran, SOP perawatan dan pembersihan alat. Membuat tempat ruang penyimpanan khusus untuk produk sayuran karena produk mudah rusak dan busuk sebelum didistribusikan kepada konsumen.
\end{abstract}

Kata Kunci : DMAIC, DPMO, six sigma

\section{PENDAHULUAN}

PT Bimandiri Agro Sedaya merupakan salah satu perusahaan berbadan hukum di Kabupaten Bandung Barat, berada di Kecamatan Lembang yang bergerak di bidang usaha pertanian, adapun jenis usaha perusahaan ini yaitu bergerak di bidang Argobisnis. Perusahaan ini adalah perusahaan yang melakukan kegiatan pengemasan sehingga dikenal sebagai perusahaan packing house. PT Bimandiri Agro Sedaya memasok kurang lebih 130 jenis komoditas berbagai jenis sayur, salah satunya adalah sayuran Jagung Kelobot, Brokoli dan Bayam Hijau banyak/sering dipesan oleh konsumen. Pada kenyataanya, masih terdapat produk defect atau cacat yang diterima oleh konsumen kecacatan ini terjadi dikarenakan faktor - faktor seperti salah sortir produk sayuran, sayuran berasal dari supplier yang dengan kualitas sayuran yang 
berbeda-beda, sayuran yang dikirim banyak luka dan hama, sedangkan standar kualitas produk sayuran yang baik biasanya tidak busuk, tidak berulat dan segar untuk dikonsumsi.

Pengendalian kualitas adalah kegiatan yang dilakukan untuk menjamin agar kegiatan produksi dan operasi yang dilaksanakan sesuai dengan apa yang direncanakan dan apabila terjadi penyimpangan, maka penyimpangan tersebut dapat dikoreksi sehingga apa yang diharapkan dapat tercapai [1]. Pengendalian kualitas adalah suatu sistem verifikasi dan penjagaan atau pengawasan dari suatu tingkat atau derajat kualitas produk atau proses yang dikehendaki dengan perencanaan yang seksama, pemakaian peralatan yang sesuai, inspeksi yang terus menerus serta tindakan korektif bilamana diperlukan [2]. Kata kualitas yang berorientasi pada kepuasan konsumen tidak harus mempunyai arti "yang terbaik" dalam dunia industri, melainkan kualitas yang berarti lebih baik dalam memuaskan kebutuhan konsumen. Tabel 1. merupakan tabel yang menunjukan data kecacatan (defect) produk sayuran [3].

Tabel 1. Produk Cacat Sayuran Jagung Kelobot,Brokoli dan Bayam Hijau bulan September-November 2019

\begin{tabular}{|c|c|c|c|c|c|c|c|c|c|}
\hline \multirow{2}{*}{ Bulan } & \multicolumn{9}{|c|}{ Item } \\
\cline { 2 - 10 } & \multicolumn{3}{|c|}{ Jagung Kolobot } & \multicolumn{3}{c|}{ Brokoli } & \multicolumn{3}{c|}{ Bayam Hijau } \\
\cline { 2 - 10 } & $\begin{array}{c}\text { Produk } \\
\text { Datang }\end{array}$ & $\begin{array}{c}\text { Produk } \\
\text { Cacat }\end{array}$ & $\begin{array}{c}\text { Present } \\
\text { ase (\%) }\end{array}$ & $\begin{array}{c}\text { Produk } \\
\text { Datang }\end{array}$ & $\begin{array}{c}\text { Produk } \\
\text { Cacat }\end{array}$ & $\begin{array}{c}\text { Present } \\
\text { ase (\%) }\end{array}$ & $\begin{array}{c}\text { Produk } \\
\text { Datang }\end{array}$ & $\begin{array}{c}\text { Produk } \\
\text { Cacat }\end{array}$ & $\begin{array}{c}\text { Present } \\
\text { ase (\%) }\end{array}$ \\
\hline Sept & $6.807,5$ & 1.116 & $16,4 \%$ & 3.986 & 470,5 & $11,8 \%$ & 3.165 & 510,5 & $16,1 \%$ \\
\hline Okt & 6.115 & 898 & $14,9 \%$ & 4.695 & 460 & $9,8 \%$ & 4.030 & 584 & $14,5 \%$ \\
\hline Nov & 6.794 & 1.177 & $17,3 \%$ & 4.057 & 440,5 & $10,9 \%$ & 4.113 & 970 & $23,6 \%$ \\
\hline Total & $19.716,5$ & 3.191 & $16,2 \%$ & 12.738 & 1.371 & $10,8 \%$ & 113.08 & $2.064,5$ & $18,3 \%$ \\
\hline
\end{tabular}

Sumber: PT Bimandiri Agro Sedaya
Berdasarkan Tabel 1 diatas dapat kita lihat bahwa permasalahan yang terjadi masih banyaknya produk sayuran cacat, maka peningkatan kualitas yang baik harus dapat memuaskan konsumen adalah salah satu cara yang dapat dilakukan agar bersaing dipasaran dengan menyelesaikan masalah mengunakan penerapan metode peningkatan kualitas. Industri mengharapkan 3.4 kegagalan per sejuta kesempatan (DPMO - Defects Per Million Opportunities [4]. Pada beberapa penelitian [5] penggunaan metode Six Sigma DMAIC telah diperoleh nilai baseline kinerja pada 4,48 sigma dengan empat jenis cacat pada produk Roti Durian Panglima, dan berdasarkan fase peningkatan menggunakan metode PFMEA, prioritas pada peningkatan produk juga terletak pada faktor manusia. Berdasarkan $\left[{ }^{6}\right]$ pengolahan data didapat nilai DPMO 3.31 sigma dengan CTQ (Critical of Quality) adalah jenis cacat kursi lecet dan penyok, ukuran tidak standar dan jahitan tidak rapi. Penerapan metode DMAIC secara tepat dapat diharapkan meningkatkan kualitas, Konsep DMAIC yang dikenal dengan siklus define, measure, analyze, improve dan control, diharapkan bisa mengurangi jumlah produk cacat, hal ini sangat menguntungkan bagi perusahaan karena bisa mengetahui faktor - faktor yang mempengaruhi produk cacat, yang dapat dijadikan sebagai acuan atau pedoman oleh pemilik tersebut dalam melakukan perbaikan sehingga dapat terkendali dan perusahaan mendapatkan respon positif dari konsumen. Keterbaharuan Penelitian adalah objek yang diteliti merupakan produk sayuran yang dikemas untuk dikirimkan kepada konsumen dalam keadaan segar tanpa pengawet sehingga perlu penanganan dengan cepat dan tepat. Penerapan metode DMAIC ini diharapkan dapat menciptakan suatu produk yang berkualitas dan tanpa adanya kecacatan. 


\section{LANDASAN TEORI}

Metode yang digunakan dalam penelitian ini adalah six sigma. Aplikasi six sigma berfokus pada cacat dan variasi, dimulai dengan mengidentifikasi unsur- unsur kritis terhadap kualitas (Critical to Quality - CTQ) dari suatu proses. Six sigma menganalisa kemampuan proses dan bertujuan menstabilkannya dengan cara mengurangi atau menghilangkan variasi- variasi. Langkah mengurangi cacat dan variasi dilakukan secara sistematis dengan mendefinisikan, mengukur, menganalisa, memperbaiki, dan mengendalikannya [ 7 ]. Metode DMAIC adalah sebuah siklus metodologi yang terstruktur secara sistematis yang bertujuan untuk mengurangi kecacatan pada suatu sistem, agar sistem tersebut bisa bekerja secara efisien dan produktif.

\section{A. Tahap Metode DMAIC}

1. Define (Penjelasan), Define adalah tahap awal dari DMAIC. Tahap ini menjelaskan tentang tema masalah yang sedang terjadi ataupun menjelaskan tentang tujuan dari studi kasus.

- SIPOC Map (Diagram Supplier, Input, Proses, Output dan Customer). SIPOC (Supplier, Input, Process, Output, Customer) adalah diagram sederhana yang memberikan gambaran umum (secara high level) untuk memahami elemen - elemen kunci sebuah proses bisnis.

- Pareto Chart. Pareto Chart merupakan salah satu tools (alat) dari QC 7 tools yang sering digunakan dalam hal pengendalian mutu.

- FMEA (Failure Mode Effect Analysis), artinya adalah analisa yang dilakukan untuk menemukan efek apa saja yang dapat berpotensi membuat kesalahan di suatu produk atau proses produksi.

- Affinity Diagram adalah suatu alat atau metode brainstorming yang menggunakan diagram untuk mengorganisasikan sejumlah besar ide - ide ke dalam hubungan alamiah mereka.Diagram Afinitas juga dapat digunakan untuk mendorong ide - ide atau pemikiran - pemikiran yang kreatif untuk penyelesaian suatu masalah.

- ERD (Entity Relation Diagram), ERD (Entity Relationship Diagram) adalah suatu model untuk menjelaskan hubungan antar data dalam basis data berdasarkan objek - objek dasar data yang mempunyai hubungan antar relasi. ERD untuk memodelkan struktur data dan hubungan antar data, untuk menggambarkannya digunakan beberapa notasi dan simbol.

2. Measure (Pengukuran), Measure adalah tahap kedua dari DMAIC. Tahap ini bertujuan untuk melakukan penilaian atau pengukuran terhadap masalah yang terjadi.

- DPMO (Defects Per Million Opportunities), DPMO adalah Defects Per Million Opportunities yaitu cacat per satu juta kesempatan. Jadi yang dimaksud dengan 3,4 DPMO adalah 3,4 cacat dalam 1 (satu) juta kesempatan. DPMO merupakan salah satu dari penilaian kapabilitas proses (Process Capability) untuk mengukur seberapa baiknya suatu proses produksi. Penilaian kapabilitas proses lainnya antara lain DPU (Defects Per Unit), Z-score (Sigma Level), Cp dan Cpk.

3. Analyze (Analisa), Analyze merupakan tahap ketiga dari DMAIC. Tahap ini bertujuan untuk melakukan analisa penyebab masalah berdasarkan prioritas tertinggi.

4. Improve (Perbaikan), Improve merupakan tahap keempat dari DMAIC. Tahap ini bertujuan untuk melakukan tindakan perbaikan setelah penyebab masalah diketahui. Dalam melakukan perbaikan tersebut, bisa menunjuk seorang penanggung jawab pekerjaan atau PIC, disertai deadline (batas waktu penyelesaiannya).

5. Control (Pengendalian), Control merupakan tahap terakhir dari DMAIC. Tahap ini bertujuan untuk mengevaluasi hasil dari proses perbaikan yang sudah dilakukan.

\section{B.Six Sigma}

Six Sigma adalah metode yang berfokus pada peningkatan kualitas , SIX SIGMA berasal dari kata SIX yang berarti 6 dan SIGMA yang merupakan satuan dari Standar Deviasi yang dilambangkan dengan simbol $\sigma$. Six Sigma juga sering disimbolkan menjadi $6 \sigma^{8}$. 
Tabel 2. Tingkatan Six Sigma

\begin{tabular}{|c|c|c|}
\hline $\begin{array}{c}\text { Tingkat } \\
\text { Pencapaian } \\
\text { Sigma }\end{array}$ & $\begin{array}{l}\text { DPMO (Defect } \\
\text { Per Million } \\
\text { Opportunities) }\end{array}$ & $\begin{array}{l}\text { Persentase } \\
\text { dari Nilai } \\
\text { Penjualan }\end{array}$ \\
\hline 1 sigma & $\begin{array}{l}691.462 \text { (sangat } \\
\text { tidak kompetitif) }\end{array}$ & $\begin{array}{l}\text { Tidak dapat } \\
\text { dihitung }\end{array}$ \\
\hline 2 sigma & $\begin{array}{c}308.538 \text { (rata-rata } \\
\text { industri } \\
\text { Indonesia) }\end{array}$ & $\begin{array}{c}\text { Tidak dapat } \\
\text { dihitung }\end{array}$ \\
\hline 3 sigma & 66.807 & $\begin{array}{c}25-40 \% \text { dari } \\
\text { penjualan }\end{array}$ \\
\hline 4 sigma & $\begin{array}{l}6.210 \text { (rata-rata } \\
\text { industri USA) }\end{array}$ & $\begin{array}{l}15-25 \% \text { dari } \\
\text { penjualan }\end{array}$ \\
\hline 5 sigma & $\begin{array}{l}233 \text { (rata-rata } \\
\text { industri Jepang) }\end{array}$ & $\begin{array}{l}5-15 \% \\
\text { penjualan }\end{array}$ \\
\hline 6 sigma & $\begin{array}{c}\text { 3,4 (industri kelas } \\
\text { dunia) }\end{array}$ & $\begin{array}{l}<1 \% \text { dari } \\
\text { penjualan }\end{array}$ \\
\hline
\end{tabular}

Sumber: Gasperz dan Fontana (2018)

Tabel 2 merupakan tabel konversi DPMO ke nilai sigma dan Tabel 2 menjelaskan arti dari tingkatan / level Six Sigma.

\section{C.DPMO}

Defect Per Million Opportunities (DPMO) termasuk salah satu pengukuran dari process performance. Dimana jika nilainya $\geq 1$ proses dikatakan potensial capable sehingga masih terdapat kecenderungan proses incapable., DPMO adalah suatu pengukuran performansi dari suatu proses yang dihitung dengan rumus berikut ini :

DPMO $=(\mathrm{D} /(\mathrm{U} \times \mathrm{O})) \times 1.000 .000$

Keterangan :

$\begin{array}{ll}\text { DPMO } & =\text { Defects Per Million } \\ & \text { Opportunities } \\ \mathrm{D} & =\text { Jumlah defect } \\ \mathrm{U} & =\text { Jumlah unit } \\ \mathrm{O} & =\text { Jumlah kesempatan yang } \\ & \begin{array}{l}\text { akan mengakibatkan cacat } \\ \text { (opportunities) }\end{array}\end{array}$

Maksud dari deffect ini sendiri adalah ketidaksesusaian dari kualitas suatu karakteristik terhadap spesifikasinya. Satuan DPMO dinyatakan dalam kesempatan per satu juta unit untuk lebih meyakinkan.

\section{D.SIPOC}

SIPOC diagram adalah tool yang digunakan tim untuk mengidentifikasi semua elemen yang relevan dalam process improvement project yang mungkin tidak tercakup dengan baik. Diagram ini mirip dan berhubungan dengan Process Mapping, namun memberikan detail yang lebih lengkap. Penjelasan dari SIPOC sendiri adalah Supplier, Input Process, Output, dan Customer :

\section{E.VOC}

VOC adalah ekspresi dari kebutuhan dan keinginan customer. Bisa specifik "Saya butuh pengiriman dalam 3 hari" bisa juga ambiguous "Pengiriman yang lebih cepat". VOC dapat dibandingkan dengan data internal (Voice of the Process) untuk menilai proses performance atau process capability kita saat ini.

\section{F.CTQ}

Setelah semua varibel yang dipandang penting oleh pelanggan didapatkan dan diberi nilai terukur (varibel terukur tersebut disebut CTQ), dengan kata lain, CTQ adalah sebuah karakteristik dari sebuah produk atau jasa yang memenuhi kebutuhan pelanggan ( internal ataupun eksternal). CTQ adalah kunci karakteristik yang dapat diukur dari sebuah produk atau proses yang harus mencapai performansi standard atau batas/limit dari spesifikasinya agar dapat memuaskan keinginan dan kebutuhan dari customer, dengan adanya CTQ ini maka improvement atau upaya desain yang dilakukan akan bersekutu dan searah dengan requirement dari customer. 


\section{METODE PENELITIAN Proses Pengambilan Data}

Proses pengumpulan data yang dilakukan antara lain sebagai berikut :

1. Observasi yaitu : Pengamatan lapangan secara langsung dalam hal ini dilakukan oleh mahasiswa dengan cara mengunjungi PT Bimandiri Agro Sedaya

2. Studi Pustaka yaitu : Mencari segala data yang berhubungan dengan permasalahan ini, yaitu dengan cara membaca dan memahami artikel ilmiah dan artikel penelitian.

3. Wawancara : Melakukan tanya jawab dengan HDR dan staf PT Bimandiri Agro Sedaya.

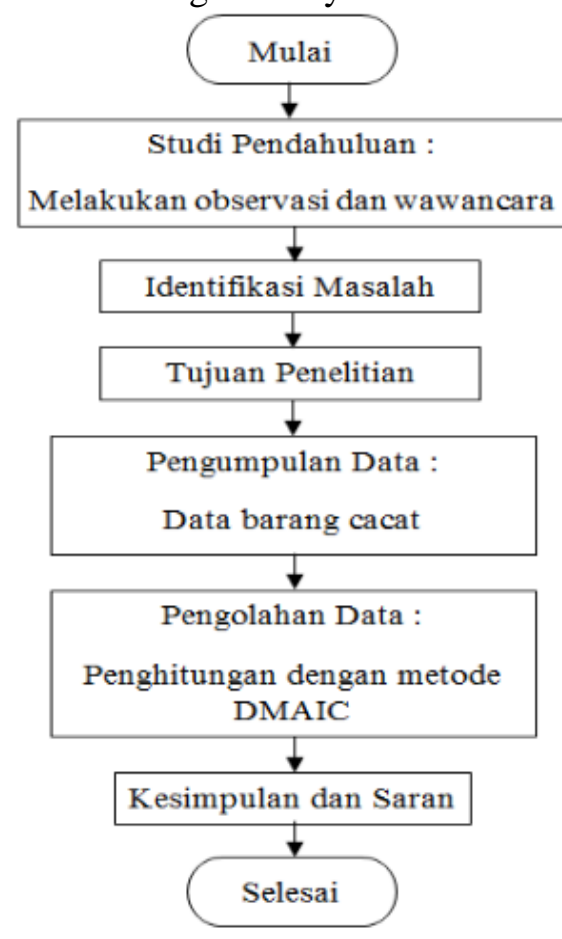

Gambar 1. Flowchart Penelitian

\section{HASIL DAN PEMBAHASAN}

\section{Define}

Define merupakan tahap identifikasi awal, dimana pada tahap ini harus dilakukan dengan akurat dan teliti dalam melihat dampak dari permasalahan yang timbul dan juga menjelaskan jenis-jenis kesalahan yang terjadi akibat proses - proses yang dilakukan. Permasalahan adalah yaitu adanya peningkatan jumlah produk cacat di tahun 2019. Dari data di atas, produk sayuran cacat ini terjadi dikarenakan oleh faktor - faktor sebagai berikut

1. Salah Sortir

Masalah ini sering terjadi dikarenakan oleh berbagai faktor, seperti minimnya penerangan, SOP yang diabaikan, kurang telitinya karyawan pada saat penyortiran.

2. Supplier yang Bervariasi

Permasalahan ini dianalisis dengan menggunakan Diagram SIPOC Pada Tabel 3, permasalahan diakibatkan dari Supplier yang bervariasi sehingga produk sayuran dari berbagai supplier ini (para petani) diperoleh dengan kualitas yang berbeda-beda sehingga besar kemungkinan produk sayur yang dikemas dan dikirim kepada konsumen akan terdapat kecacatan.

Tabel 3 Diagram SIPOC

\begin{tabular}{|c|c|c|c|c|}
\hline Supplier & Input & Process & Output & Customers \\
\hline Para Petani & $\begin{array}{l}\text { Barang yang } \\
\text { dipesan oleh } \\
\text { konsumen } \\
\text { untuk diolah }\end{array}$ & \begin{tabular}{|c|}
$\begin{array}{c}\text { Barang diterima, ditimbang dan } \\
\text { dicatat }\end{array}$ \\
$\begin{array}{c}\text { Barang disotir, degrading dan } \\
\text { ditrimming }\end{array}$ \\
Barang dicek \\
\\
Barang dilabeli \\
\\
Barang dicek kembali \\
$\downarrow$ \\
Barang dikemas \\
\end{tabular} & $\begin{array}{c}\text { Barang yang } \\
\text { dipesan oleh } \\
\text { konsumen } \\
\text { dan siap } \\
\text { untuk } \\
\text { dikirimkan }\end{array}$ & Supermarket \\
\hline
\end{tabular}

Sumber: Penulis diolah

Langkah selanjutnya adalah identifikasi jenis Rework atau Critical To Quality (CTQ) dan melakukan Voice of Customer (VOC). Untuk mendapatkan data untuk VOC Penulis melakukan survei kepada 20 pelanggan yang pernah melakukan pemesanan kepada PT Bimandiri Agro Sedaya mengenai kecacatan yang pernah dialami. Penulis melakukan survei dengan membagikan kuesioner, dalam kuesioner tersebut memberikan pertanyaan - pertanyaan mengenai kecacatan yang pernah dialami saat melakukan pemesanan dalam bentuk Tabel 4 sebagai berikut. 
Tabel 4. Tabel VOC

\begin{tabular}{|c|l|c|c|c|}
\hline No & \multicolumn{1}{|c|}{ Atribut } & $\begin{array}{c}\text { Jumlah } \\
\text { Responden }\end{array}$ & $\%$ & $\begin{array}{c}\% \\
\text { Kumulatif }\end{array}$ \\
\hline 1 & $\begin{array}{l}\text { Barang dikirim jumlahnya tidak } \\
\text { sesua dengan pesanan }\end{array}$ & 2 & $6,9 \%$ & $6,9 \%$ \\
\hline 2 & $\begin{array}{l}\text { Produk yang dikirim terdapat } \\
\text { serangga }\end{array}$ & 3 & $10,3 \%$ & $17,2 \%$ \\
\hline 3 & $\begin{array}{l}\text { Produk yang dikirim berbeda- } \\
\text { beda kualitas }\end{array}$ & 5 & $17,2 \%$ & $34,5 \%$ \\
\hline 4 & $\begin{array}{l}\text { Produk yang dikirim mengalami } \\
\text { busuk }\end{array}$ & 7 & $24,1 \%$ & $58,6 \%$ \\
\hline 5 & $\begin{array}{l}\text { Produk yang dikirim memiliki } \\
\text { fisik yang tidak sempurna (ada } \\
\text { luka) }\end{array}$ & 12 & $41,4 \%$ & $100 \%$ \\
\hline \multicolumn{2}{|c|}{ jumlah } & 29 & $100 \%$ & $100 \%$ \\
\hline
\end{tabular}

Sumber: Penulis diolah

Tabel 4 merupakan hasil survei yang dilakukan dan data diolah tersebut dalam bentuk Diagram Pareto pada Gambar 2

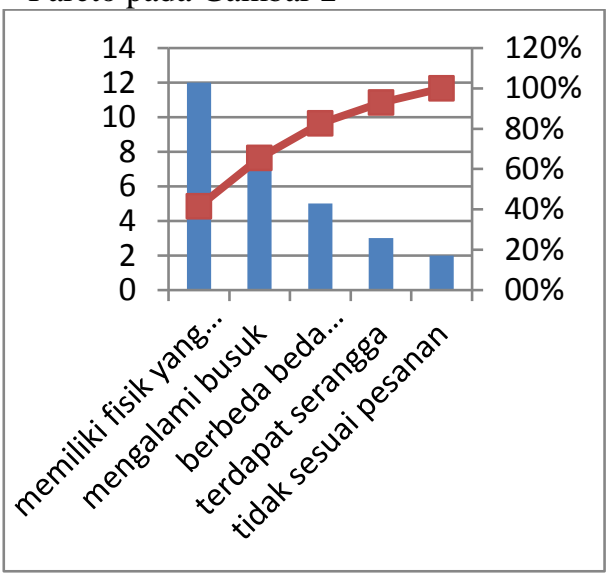

Gambar 2. Diagram Pareto Sumber:Penulis diolah

Berdasarkan Diagram Pareto di atas terlihat bahwa $80 \%$ kecacatan yang paling sering terjadi yaitu sayuran memiliki fisik yang tidak sempurna (ada luka) dan sayuran mengalami pembusukan, terdapat juga sayuranmemiliki fisik yang tidak sempurna (ada luka) memiliki presentase $41,4 \%$ dan produk mengalami pembusukan memiliki presentase $24,1 \%$ Sehingga sayuran memiliki fisik yang tidak sempurna (ada luka) dan sayuran mengalami pembusukan sebagai Critical to Quality (CTQ) yang paling diperhatikan terutama produk memiliki fisik yang tidak sempurna (ada luka).

CTQ tree pada produk memiliki fisik yang tidak sempurna (ada luka) dan sayuran yang mengalami pembusukan. CTQ tree (Critical To Quality tree) adalah sebuah tools yang biasa digunakan untuk menguraikan atau mendekomposisi requirement customer yang cukup luas menjadi requirement yang terkuantifikasi dan lebih mudah memprosesnya.

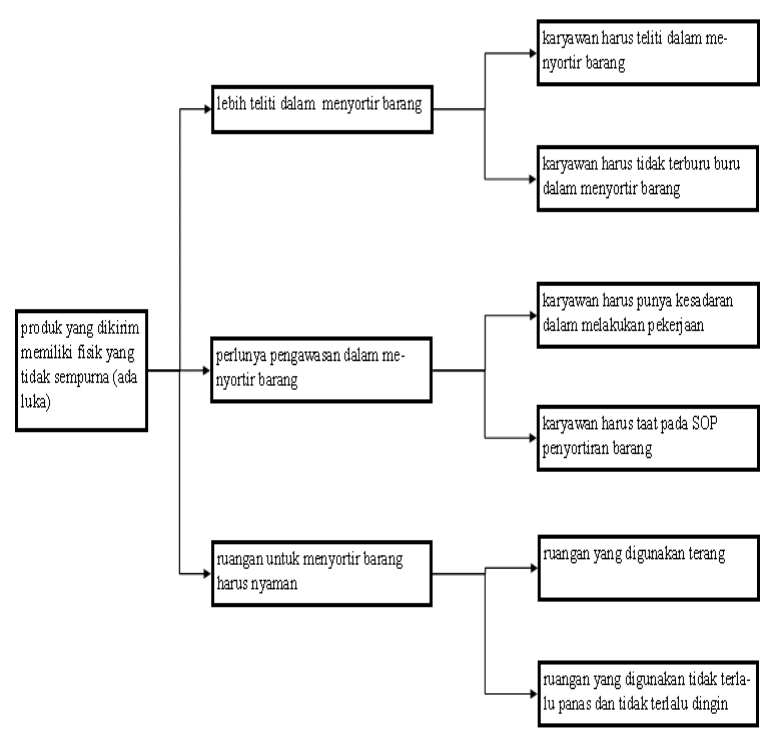

\section{Gambar 3. CTQ Tree Produk Memiliki Fisik yang Tidak Sempurna Sumber: Penulis diolah}

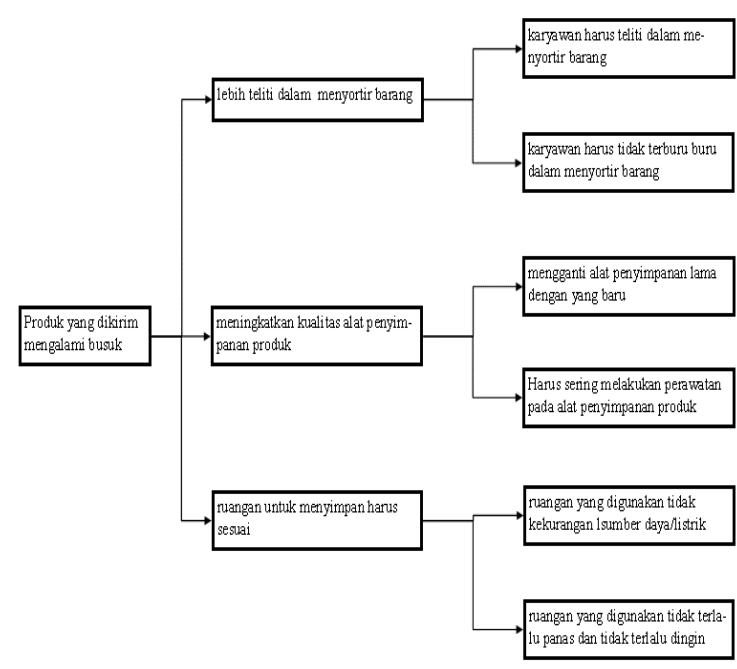

Gambar 4. CTQ Tree Produk

Mengalami Pembusukan Sumber:Penulis diolah 


\section{Measure}

Tahap ini dilakukan pengukuran tingkat kecacatan yang terjadi pada proses pengolahan di PT Bimandiri Agro Sedaya periode bulan September - November 2019 yang dinyatakan dalam DPMO dan dikonfersikan dalam ukuran sigma. Berikut adalah penghitungan nilai DPMO dan sigma :

Penghitungan di atas menggunakan rumus:

$\mathrm{DPMO}=(\mathrm{D} /(\mathrm{U} \times \mathrm{O})) \times 1.000 .000$

Keterangan :

$\begin{array}{ll}\text { DPMO } & =\text { Defects Per Million } \\ & \text { Opportunities } \\ \mathrm{D} & =\text { Jumlah defect } \\ \mathrm{U} & =\text { Jumlah unit } \\ \mathrm{O} & =\text { Jumlah kesempatan yang }\end{array}$

akan mengakibatkan cacat

Contoh penghitungan :

DPMO Jagung Kelobot

$=(3191 /(19716,5 \times 5)) \times 1.000 .000$

$=32.368,83$

Berikut adalah penghitungan nilai DPMO dan sigma secara keseluruhan :

Tabel 5. Perhitungan DPMO dan Nilai Sigma

\begin{tabular}{|c|c|c|c|c|c|r|}
\hline no & jenis produksi & $\begin{array}{c}\text { total } \\
\text { produk } \\
\text { datang }\end{array}$ & $\begin{array}{c}\text { total } \\
\text { produk } \\
\text { cacat }\end{array}$ & CTQ & DPM0 & Sigma \\
\hline 1 & jagung kelobot & $19.716,5$ & 3.191 & 5 & $32.368,83$ & 3,35 \\
\hline 2 & brokoli & 12.738 & 1.371 & 5 & $21.526,14$ & 3,52 \\
\hline 3 & bayam hijau & 11.308 & $2.064,5$ & 5 & $36.513,97$ & 3,29 \\
\hline \multicolumn{2}{|c|}{ jumlah } & $43.762,5$ & $6.626,5$ & & $90.408,94$ & \\
\hline \multicolumn{2}{|c|}{ rata - rata } & $14.587,5$ & $2.208,83$ & & $30.136,31$ & 3,39 \\
\hline
\end{tabular}

Sumber: Penulis diolah

Perhitungan pada Tabel 5 menggunakan data dari Sayuran Jagung Kelobot, Brokoli, dan Bayam Hijau pada bulan September - November 2019 dapat disimpulkan bahwa rata - rata nilai DPMO sebesar 30.136, 31 yang berarti bahwa dalam satu juta kesempatan akan terdapat 30.136, 31 kemungkinan proses tersebut cacat, dan nilai sigma yang di dapat sebesar 3, 39 .

\section{Analyze}

Tahap ini merupakan tahap mencari dan menemukan akar atau penyebab dari permasalahan. Pada tahap sebelumnya sudah didapat prioritas permasalahan yang akan diselesaikan. Dari permasalahan tersebut, maka dapat dianalisis akar penyebabnya adalah berasal dari pengolahan data sebelumnya pada tahap define. Penulis mendapatkan beberapa jenis kecacatan yang terjadi dan jenis cacat karena produk yang dikirim memiliki fisik yang tidak sempurna (ada luka) dan produk mengalami pembusukan dikatakan sebagai Critical to Quality (CTQ) yang paling diperhatikan. Berikut adalah analisis permasalahan produk yang dikirim memiliki fisik yang tidak sempurna (ada luka) :

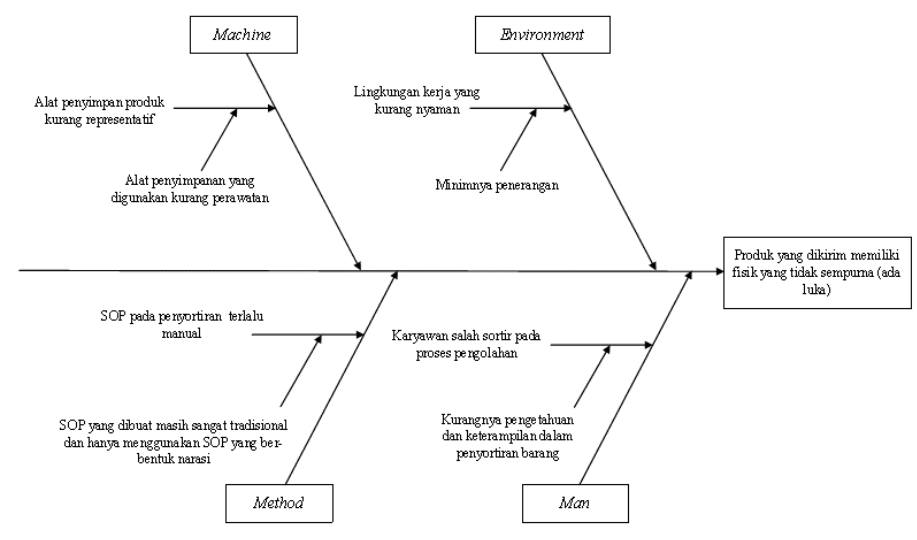

\section{Gambar 5. Fishbone Sayuran Fisik yang Tidak Sempurna Sumber:Penulis diolah}

Analisis permasalahan sayuran yang dikirim memiliki fisik yang tidak sempurna (ada luka) dapat dilihat melalui diagram fishbone pada Gambar 5, sedangkan analisis permasalahan produk yang dikirim mengalami pembusukan dapat dilihat pada Gambar 6. 


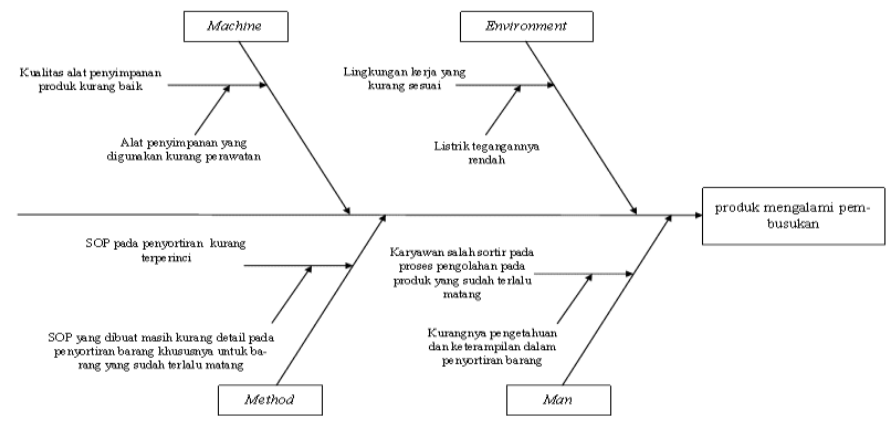

Gambar 6 merupakan fishbone diagram yang menerangkan tentang apa yang menjadi penyebab sayuran mengalami pembusukan dilihat berdasarkan man,method,machine dan environment.

\section{Pengolahan Data}

Berdasarkan hasil analisis DMAIC di atas, pada tahap define ada 2 permasalahan yang muncul pada penyebab kecacatan yaitu salah sortir dan mutu sayuran yang bervariasi karena berasal dari supplier yang berbeda-beda, kemudian diolah dalam Tabel SIPOC, setelah itu dilakukan identifikasi jenis Rework atau Critical To Quality (QTC) dan melakukan Voice of Customer (VOC). Survei kepada 20 pelanggan yang pernah melakukan pemesanan kepada PT Bimandiri Agro Sedaya, dan menanyakan pengalaman mereka terhadap kecacatan sayuran yang pernah dialami oleh pelanggan, hasilnya terdapat Tabel 3 sayuran yang memiliki fisik yang tidak sempurna (ada luka) dan produk mengalami pembusukan sebagai Critical to Quality (CTQ) yang paling diperhatikan terutama produk memiliki fisik yang tidak sempurna (ada luka).

Pada Gambar 3 CTQ tree dari produk memiliki fisik yang tidak sempurna (ada luka), CTQ tree ini berfungsi untuk meminimalisasi permasalahan dimana seharusnya karyawan perlu lebih teliti dalam menyortir, karyawan harus diawasi dalam melakukan penyortiran, ruangan untuk menyortir barang harus nyaman. Gambar 4 CTQ tree dari sayuran yang mengalami pembusukan, CTQ tree ini untuk berfungsi untuk mengurangi sayuran mengalami pembusukan yaitu karyawan harus lebih teliti dalam menyortir barang, meningkatkan alat penyimpanan produk, ruangan dengan penyejuk khususnya untuk menyimpan sayuran harus sesuai.

Pada tahap measure Penulis melakukan pengukuran tingkat kecacatan yang terjadi dinyatakan dalam DPMO dan dikonfersikan dalam ukuran sigma, untuk penghitungan DPMO ini Penulis mendapatkan 5 CTQ antara lain sayuran yang dikirim tidak sesuai dengan pesanan, selain itu sayuran yang dikirim terdapat serangga, sayuran yang dikirim berbeda - beda kualitasnya, sayuran yang dikirim mengalami pembusukan dan sayuran yang dikirim memiliki fisik yang tidak sempurna (ada luka). Berdasarkan Tabel 5 dapat bahwa jumlah nilai DPMO sebesar 90.408, 94 dan rata - rata nilai DPMO sebesar 30.136, 31 yang berarti bahwa dalam satu juta kesempatan akan terdapat 30.136, 31 kemungkinan proses tersebut menghasilkan cacat, dan nilai sigma yang di dapat rata - rata sebesar 3,39. Sayuran Bayam Hijau didapatkan level sigma yang paling rendah dibandingkan dengan produk lainnya yakni sebesar 3, 29. Sayuran Brokoli didapatkan level sigma yang paling tinggi dibandingkan dengan produk lainnya yakni sebesar 3,52.

Pada tahap analyze Penulis mengolah dengan diagram fishbone dan Penulis menemukan beberapa akar penyebab masalah yang menyebabkan permasalahan produk yang dikirim memiliki fisik yang tidak sempurna (ada luka), yaitu dari bagian man, method, environment dan machine. Yaitu :

1. Manusia (Man)

Karyawan melakukan salah sortir, hal ini disebabkan karena kurangnya pengetahuan dan ketrampilan karyawan dalam menyortir barang.

2. Metode (Method)

SOP pada penyortiran manual, hal ini disebabkan karena SOP yang dibuat masih sangat tradisional dan hanya menggunakan SOP yang berbentuk narasi.

3. Lingkungan (Environment)

Produktivitas karyawan dalam menyortir barang menurun dikarenakan lingkungan kerja yang tidak nyaman, hal tersebut dapat disebabkan oleh minimnya penerangan pada ruangan di bagian pengolahan.

4. Peralatan (Machine)

Terjadinya alat penyimpanan produk yang kurang representatif, hal ini disebabkan karena kurangnya perawatan pada alat penyimpanan sayuran.

Beberapa akar penyebab masalah yang menyebabkan permasalahan produk yang dikirim mengalami pembusukan, yaitu dari bagian man, method, environment dan machine. Yaitu :

1. Manusia (Man) 
Karyawan melakukan salah sortir pada proses pengolahan sayuran yang sudah terlalu matang, hal ini disebabkan karena kurangnya pengetahuan dan ketrampilan karyawan dalam menyortir barang.

2. Metode (Method)

SOP pada penyortiran kurang terperinci, hal ini disebabkan karena SOP yang dibuat masih kurang detail mengenai penyortiran barang pada sayuran yang sudah terlalu matang.

3. Lingkungan (Environment)

Produktivitas karyawan dalam menyortir barang terganggu dikarenakan lingkungan kerja yang kurang sesuai, hal tersebut dapat disebabkan oleh listrik tegangannya terlalu rendah.

4. Peralatan (Machine)

Terjadinya alat penyimpanan produk yang kurang baik, hal ini disebabkan karena kurangnya perawatan pada alat penyimpanan sayuran.

\section{KESIMPULAN}

Berdasarkan dari pembahasan yang telah dilakukan pada bab sebelumnya dapat diambil kesimpulan sebagai berikut :

1. Penyebab Utama produk sayuran cacat adalah sayuran yang dikirim memiliki fisik yang tidak sempurna (ada luka) dan sayuran mengalami pembusukan. Upaya yang dilakukan adalah memberikan pelatihan dan meningkatkan kemampuan karyawan dalam mengolah produk sayuran, membuat SOP penyortiran produk sayuran,SOP penyimpanan sayuran, dan membuat tempat penyimpanan khusus untuk produk sayuran karena produk mudah rusak dan busuk.

2. Rata - rata nilai DPMO sebesar 30.136, 31 pada sayuran Jagung Kelobot, Brokoli dan Bayam Hijau,Artinya jika barang masuk dari suppluer sebanyak 1.000.000 maka ada 30.136 produk sayuran yang tidak memenuhi standar. Nilai DPMO dikonversi ke nilai sigma menjadi rata - rata sebesar 3,39. Menurut Gaspersz (2002) nilai Sigma 3,39 mengindikasikan perlu perbaikan proses untuk meningkatkan kualitas produk dan kapabilitas proses dan besarnya biaya yang harus dikeluarkan untuk menyelesaian atau menangani kegagalan dan atau kerusakan dalam proses adalah $25-40 \%$ dari penjualan

\section{REFERENSI}

[1] Assauri, Sofyan. (2004). Manajemen Produksi dan Operasi. Jakarta: Lembaga Penerbit Fakultas Ekonomi Universitas Indonesia

[2] Ginting, Rosnani.2007. Production System. Graha Ilmu. Yogyakarta.

[3] Feigenbaum, A. V. 1992. Kendali Mutu Terpadu. Penerbit Erlangga. Gaspersz, V. 1997. Manajemen Kualitas Dalam Industri Jasa. PT Gramedia. Pustaka Utama.

[4] Sukardi, Effendi U, Astuti DA. 2011. Aplikasi Six Sigma Pada Pengujian Kualitas Keripik Apel. Jurnal Teknologi Pertanian. 1(12): 1

[5] Suci, Yurin Febria. dkk. 2017. "Penggunaan Metode Seven New Quality Tools dan Metode DMAIC Six Sigma pada Penerapan Pengendalian Kualitas Produk (Studi Kasus : Roti Durian Panglima Produksi PT Panglima Roqiiqu Group Samarinda)" Jurnal Eksponential. 8(1). 27 - 36

[6] Ahmad, Fandi. 2019. "Six Sigma DMAIC Sebagai Metode Pengendalian Kualitas Produk Kursi pada UKM". Jurnal Integrasi Sistem Industri. 6(1). $11-17$

[7] Vanani, Iwan dan Emilasari, Desy.2007. Aplikasi six Sigma pada produk clear file di Perusahaan Stationary.Jurnal Teknik Industri.Fakultas Teknologi Industri, Universitas Kristen Petra. (27-36)

[8] Gaspersz, V. dan Fontana, A. (2011). Lean Six Sigma for Manufacturing and Service Industries, Waste Elimination and Continous Cost Reduction, Edisi Kedua. Bogor : Vinchristo Publication. 
